\title{
Article \\ RURAL ELECTRIFICATION OF SOMALIA USING WT-PV-DG-BATTERY HYBRID SYSTEM
}

\author{
Swathi Salim Kumar ${ }^{1, \ddagger}$, Richard Blanchard ${ }^{2, \ddagger, *}$ \\ 1 Wolfson School Mechanical, Manufacturing and Electrical Engineering, Loughborough University, \\ Loughborough LE11 3TU, UK; swathisk@hotmail.com \\ 2 Centre for Renewable Energy Systems Technology (CREST), Wolfson School Mechanical, Manufacturing and \\ Electrical Engineering, Loughborough University, Loughborough LE11 3GR, UK; r.e.blanchard@lboro.ac.uk \\ * Correspondence: r.e.blanchard@lboro.ac.uk \\ $\ddagger$ These authors contributed equally to this work.
}

check for updates

Citation: Salim Kumar, S; Blanchard, R. Title. Journal Not Specified 2021, 1, 0. https://doi.org/

Received:

Accepted:

Published:

Publisher's Note: MDPI stays neutral with regard to jurisdictional claims in published maps and institutional affiliations.

Copyright: (C) 2020 by the authors. Licensee MDPI, Basel, Switzerland. This article is an open access article distributed under the terms and conditions of the Creative Commons Attribution (CC BY) license (https:/ / creativecommons.org/licenses/by/ $4.0 /)$.
Abstract: Around 14\% of the global population does not have access to electricity. About $95 \%$ of those are living in rural Sub-Saharan Africa. Often in these regions, diesel generators are the only source of electricity. The operating cost of these diesel generators is high. However, solar and wind energy are available in most of African countries. This study presents the analysis of designing an off-grid hybrid system with a wind turbine, PV, diesel generator, and battery to power a hospital, school, and 200 household village in four locations across Somalia. The research investigated the availability of wind-solar resources in selected locations. Designing of the system and economictechnical calculations were performed using HOMER. The selection of the optimum design was based on the Cost of Electricity and Net Present Cost. The results show that for Kabaal and Ceel Buur, a WT-PV-DG-Battery is the optimal system as the wind resource in these regions is high. For Saakov and Baki, a PV-DG-Battery system proves to be optimum as the wind resource is limited here. The study also evaluated the control strategy and proved that combined dispatch was the most cost-effective for these locations. The study concluded that hybrid systems are more economical than diesel systems.

Keywords: Micro-grid, Rural Electrification, HOMER, Control strategy, Sensitivity analysis

\section{Introduction}

In spite of recently increased electrification, large numbers of people are still living in the dark. For example, around 600 million Africans lack access to electricity [1], and the average electrification rate is only $45 \%$ [2]. People living in these regions are poor and use diesel generators for electricity. Whilst electricity access does not necessarily mean life will improve, under development in the sector holds back progress, and problems in health, education, and livelihoods are exasperated. For example, in the health sector, an unreliable power supply can even cause loss of life. Surgeries can be delayed, and it is reported that that figures for maternal mortality are higher in African Countries than the rest of the world.[3] These can be avoided by providing a reliable and consistent power supply. Schools and households also experience difficulties due to electricity shortages. The excessive use of conventional systems like diesel generators, increase health problems and contribute to global warming. In such places where there is no grid, or the connection is weak, off-grid systems are an optimal solution. The off-grid renewable system can consist of individual renewable energy technologies (RET) such as wind or solar with battery energy storage. In addition, they can be hybridized with more than one RET and even supported by a backup diesel generator (DG). Options on the system can be modelled and optimized to find the best solution to the problem.[4] In Africa, where the cost to extend an existing grid to a remote location is very expensive, and the return on investment is low, then there is an opportunity for RET hybrid off-grid systems if an economical option 
can be found. The cost of electricity in most African countries is so high [5]. Despite having good wind, solar resources, development in the renewable sector is so low, and green-house emission in these regions is high. Utilising these non-conventional resources has the potential to provide a cheap reliable source of electricity in these countries.

The aim of this study was to investigate opportunities for hybrid off-grid systems to solve electricity assess issues in Somalia. The objectives were to identify and characterize the power requirements and demand profiles in Somalia. To then evaluate the availability of renewable energy sources and to develop a model of the off-grid system based on the load and resources. Finally, an economic evaluation was produced to yield optimal solutions. Somalia has low electricity access and what appears to be good solar and wind resources for hybrid systems. Four regions of Somalia with different climatic conditions were considered for this study. We simulated the hybrid system selected, and the technoeconomic analysis was obtained. The load calculation for each location was based on a reasonable assumption of a village with a health clinic, school, and 200 households and a deferrable load for water pumping. This would enable a direct comparison of the outcomes for the different objectives to develop an optimal hybrid system. The techno-economic feasibility of the four locations was studied, including determining the size of the system, state of charge of the battery, the annual energy consumption, and the renewable energy percentage. The control strategy was studied carefully. The economic analysis was used to determine the Levelized cost of electricity (LCOE), net present cost (NPC), an initial capital cost. Emissions were also obtained from the analysis. A sensitivity analysis of the optimal solution of Kabaal was studied using wind and solar resources, load growth, discount rate, fuel cost, wind turbine, and PV capital cost as sensitivity parameters. The findings has the potential to be useful in planning off-grid systems in different climate zones of Somalia and beyond.

\section{Materials and Methods}

The methodology is divided into six sections based on the objectives, i.e., location context, load demand, availability of renewable energy resources, system description and component modelling, economic calculations, cost optimization, techno-economic constraints, sensitivity analysis.

\subsection{Location context}

The location for this study was selected as Somalia. The Federal Republic of Somalia is located at the horn of Africa. Bordered by Ethiopia to the west, the Gulf of Aden to the northern side the Guardafui channel, Somali Sea to the east, and by Kenya to the southwest.

1.png 1.pdf 1.jpg 1.mps 1.jpeg 1.jbig2 1.jb2 1.PNG 1.PDF 1.JPG 1.JPEG 1.JBIG2 1.JB2 1.eps

Figure 1. Somalia Map

The electrification rate of Somalia is $32.95 \%$. The rural estimated electrification rate is $4 \%$, and the urban electrification rate is about $33 \%$. The cost of electricity is high and ranges from 0.5- $1.5 \$ / \mathrm{kWh}$. Somalia has a coastline of about $\$ 3300 \mathrm{~km}$ and is shown to have good wind and solar re-sources, which are yet to be exploited. Somalia has one of the highest resource potential among African countries for wind and solar energy. Limited regulations, monopoly distribution control, poor infrastructure holds back development in renewable sector.[6] For this study, four locations in Somalia were considered, namely Kabaal (1), Ceel Buur (2), Saakov (3), and Baki (4), as shown in figure 1.

\subsection{Load demand}

Two types of loads were considered for this study. The primary load that should be met immediately and deferrable loads that can be delivered and the timing is not important. The load can be calculated as the: Energy consumption is given by $\mathrm{E}(\mathrm{kWh} /$ day $)=$ the number of appliances $(\mathrm{n})$ power rating $(\mathrm{kW})$ no. of hours of operation. In this study, the primary loads are that of a health clinic, school, and 200 rural households. 


\subsubsection{Health clinic load}

The health clinic is an essential load as the electricity supply must be continuous without any outages. It is assumed, services are provided to treat the surrounding communities. The energy need for this rural healthcare is considered relatively low as the availability of medical equipment is low in these locations. Rural healthcare has been classified into three levels, according to the United States Agency for International Development.[7] Category 1: Limited services and staff with an electricity demand of $5-10 \mathrm{kWh} /$ day. Category 2 : Medical equipment will be similar to the category one but differs in terms of the frequency of usage of the equipment. Electricity demand is estimated to be moderate, $10-20 \mathrm{kWh} /$ day. Category 3: A greater number of beds and contains more diagnostic devices such as blood typing equipment, $\mathrm{X}$-ray machine, and multiple refrigerators. The average demand is estimated to be $20-30 \mathrm{kWh} /$ day. The health clinic considered for this study falls in category 3.

Table 1. Hospital Load.

\begin{tabular}{lllll}
\hline Item & Quantity & Rated Power(W) & Hours Operated & Energy Used(kWh/day) \\
\hline Lighting CFL(Indoor) & 10 & 15 & 7 & 1.05 \\
Lighting CFL (outdoor) & 5 & 40 & 12 & 2.40 \\
Fans & 6 & 60 & 18 & 6.48 \\
Refrigerator & 3 & 130 & 24 & 9.36 \\
Lab apparatus & 2 & 250 & 5 & 2.5 \\
Other lab apparatus & 1 & 1200 & 3 & 3.60 \\
\hline
\end{tabular}

2.png 2.pdf 2.jpg 2.mps 2.jpeg 2.jbig2 2.jb2 2.PNG 2.PDF 2.JPG 2.JPEG 2.JBIG2 2.JB2 2.eps

Figure 2. Hourly load variation of Health Clinic

The load of each equipment is presented in table 1 . The total load of the study health clinic is $27.25 \mathrm{kWh} /$ day. The peak load was estimated at $2.68 \mathrm{~kW}$. Figure 2 shows the hourly load variation of the health clinic. The load factor, as estimated by HOMER, was 0.35 . Random variability was taken as $5 \%$ day to day and $5 \%$ step to step for this load profile, and the peak load will rise to $3.27 \mathrm{~kW}$. This is because the number of patients visiting the clinic is greater around mid-day. The load demand is assumed constant throughout the year.

\subsubsection{Household and School load}

The next load taken into consideration in this study was that of households located in the selected area. This load is carefully selected after research on African households.[8] In Somalian rural households, the electrical equipment is limited. The supply of electricity is often poor. A total of 200 households were considered for this study. The load profile of an individual Somalian household is shown in table 2. Education is important for the social and economic advancement of a country. In order to have a quality education, a reliable supply of electricity is essential. Most of rural Africa lacks electricity in schools. In this study, an average-sized school is considered, which has 12 classrooms, two offices, and four toilets. [9] Total load breakdown of the school load is shown in table 3. The estimated total load of the selected household is $0.895 \mathrm{kWh} /$ day. The total load of school was estimated to be $1.465 \mathrm{kWh} /$ day with a peak of $0.325 \mathrm{~kW}$. The highest energy consumed by households was during 19:00 to 22:00, which is considered the peak time. 
Table 2. Household Loads.

\begin{tabular}{lllll}
\hline Item & Quantity & Rated Power(W) & Hours Operated & Energy Used(kWh/day) \\
\hline Lighting & 4 & 15 & 6 & 0.36 \\
Fan & 1 & 60 & 4 & 0.24 \\
TV & 1 & 65 & 4 & 0.26 \\
Radio & 1 & 5 & 3 & 0.015 \\
Charger & 2 & 5 & 2 & 0.02 \\
\hline
\end{tabular}

Table 3. School Loads.

\begin{tabular}{lllll}
\hline Item & Quantity & Rated Power(W) & Hours Operated & Energy Used(kWh/day) \\
\hline Lighting & 6 & 15 & 4 & 0.36 \\
Fan & 2 & 60 & 5 & 0.60 \\
TV & 1 & 80 & 2 & 0.16 \\
Radio & 1 & 5 & 5 & 0.025 \\
Charger & 3 & 20 & 5 & 0.30 \\
Microphone & 1 & 20 & 1 & 0.02 \\
\hline
\end{tabular}

3.png 3.pdf 3.jpg 3.mps 3.jpeg 3.jbig2 3.jb2 3.PNG 3.PDF 3.JPG 3.JPEG 3.JBIG2 3.JB2 3.eps

Figure 3. Hourly load variation of School and 200 Household

For feeding into HOMER, the School load and total household load of 200 houses were taken as a single load, which together comprised of $167.78 \mathrm{kWh} /$ day and the peak $20.88 \mathrm{~kW}$. Day to day variability is $5 \%$, and the time step variability is also taken as $5 \%$. The load factor is 0.33 . Figure 3 shows the load variation per hour of School and 200 households.

\subsubsection{Deferrable load}

This type of load is given secondary priority and is fulfilled after primary loads are met. In this study, the water pump was considered which supply water to the village, school, and health clinic. The quantity of water need is $5 \mathrm{~m}^{3}$ per day. For satisfying the need, two pumps were selected, which have a capacity of $550 \mathrm{~W}$ each. It operates daily for 5 hours, and the peak load is $1.1 \mathrm{~kW}$. A storage capacity of three days was considered. The energy needed to pump water is calculated by,[10] The energy needed $(\mathrm{kWh})=$ No of pumps $\times$ storage days $\times$ rated capacity of pumps $\times$ number of hours in operation. The energy consumption was $16.50 \mathrm{kWh}$. The annual average load per day is $5.5 \mathrm{kWh} /$ day, and the minimum load ratio was taken to be $65 \%$.

\subsection{Availabiltiy of renewable energy resources}

Somalia enjoys good solar radiation and very good wind energy resource. Solar GHI and wind resources were crucial in accurately designing the system. The solar radiation data was obtained from the National Renewable Energy Laboratory database for the four selected locations [11]. Wind data was obtained from the Global Wind Atlas (GWA).[12]

\subsubsection{Solar GHI Data}

Solar GHI radiation and ambient temperature determine the power output of solar PV. For the location Kabaal, the monthly average GHI radiation is $5.63 \mathrm{kWh} / \mathrm{m}^{2} /$ day. August has the highest solar radiation. The average temperature of the location was measured at $27.2 \mathrm{C}$. For location Ceel Buur, the average solar radiation is $5.69 \mathrm{kWh} / \mathrm{m}^{2} / \mathrm{day}$, and the average temperature of the location is $27.71 \mathrm{C}$. In southern Somalia, i.e., Saakov, the average solar radiation is $5.86 \mathrm{kWh} / \mathrm{m}^{2} /$ day and has a temperature of $27.85 \mathrm{C}$. Baki has a high average solar radiation of $5.98 \mathrm{kWh} / \mathrm{m}^{2} /$ day and an average temperature of 26.33C. See figures 4 and 5 . 
4.png 4.pdf 4.jpg 4.mps 4.jpeg 4.jbig2 4.jb2 4.PNG 4.PDF 4.JPG 4.JPEG 4.JBIG2 4.JB2 4.eps

Figure 4. Solar GHI Data

5.png 5.pdf 5.jpg 5.mps 5.jpeg 5.jbig2 5.jb2 5.PNG 5.PDF 5.JPG 5.JPEG 5.JBIG2 5.JB2 5.eps

Figure 5. Temperature Data

\subsubsection{Wind data}

The GWA 3.0 gave wind speed at anemometer heights of $10 \mathrm{~m}, 50 \mathrm{~m}, 100 \mathrm{~m}, 150 \mathrm{~m}$, and $200 \mathrm{~m}$. The $50 \mathrm{~m}$ anemometer height was taken for this study, see Figure 6 . From the data obtained, Kabaal has the windiest location at $7.12 \mathrm{~m} / \mathrm{s}$ average wind speed; on the other hand, Saakov has the lowest wind potential of $4.77 \mathrm{~m} / \mathrm{s}$ average.

6.png 6.pdf 6.jpg 6.mps 6.jpeg 6.jbig2 6.jb2 6.PNG 6.PDF 6.JPG 6.JPEG 6.JBIG2 6.JB2 6.eps

Figure 6. Wind Speed Data

\subsection{System description and component modelling}

\subsubsection{Wind turbines}

In this study, the wind turbine used is a $15 \mathrm{~kW}$ machine manufactured by Enbreeze $\mathrm{GmbH}$, Germany. It is a turbine designed to work at low- average wind conditions. The rated power is $15 \mathrm{~kW}$ with a cut in speed of $2.5 \mathrm{~m} / \mathrm{s}$ and a hub height of $20 \mathrm{~m}$. The lifetime of the turbine is considered as 20 years. The capital cost of the turbine is $\$ 88,221$. The operation and maintenance cost of the turbine is $\$ 496$ per year [13]. The electrical power output of a wind turbine is obtained by [3]

$$
P=1 / 2 \rho A V^{3} \eta
$$

The wind speed at hub height is given by,

$$
U_{h u b}=U_{a} \times\left[\frac{\ln \left(z_{\frac{h u b}{z_{0}}}\right)}{\ln \left(z_{\frac{a}{z_{0}}}\right)}\right]
$$

Where $U_{h u b}$ is the velocity at hub height, $U_{a}$ is the velocity at anemometer height, $Z_{h u b}$ is the hub height of the turbine, $Z_{a}$ is the anemometer height and $Z_{0}$ is the surface roughness length. The power curve of the wind turbine is shown in figure 7 . Density correction was calculated by HOMER using the following equation,[14]

7.png 7.pdf 7.jpg 7.mps 7.jpeg 7.jbig2 7.jb2 7.PNG 7.PDF 7.JPG 7.JPEG 7.JBIG2 7.JB2 7.eps

Figure 7. Wind turbine power curve

$$
P_{W T}=\left(\frac{\rho}{\rho_{0}}\right) \cdot P_{W T, s t c}
$$

Where $P_{W T}$ is the output of the turbine, $P_{W T, s t c}$ is the power output at standard test condition, $\rho$ is the actual air density and $\rho_{0}$ in is the air density at the standard test condition.

\subsubsection{PV system}

The PV panel selected in this study is a mono-crystalline flat type, manufactured by Canadian Solar. [15] The rated capacity is $0.295 \mathrm{~kW}$, temperature coefficient -0.390 , and operating temperature is $45 \mathrm{C}$. The efficiency of this solar panel is $18.02 \%$. Furthermore, the lifetime is considered to be 25 years with a De-rating factor of $80 \%$. There is no tracing or MPPT system, and the ground reflectance is taken as $20 \%$. PV depends upon the GHI 
radiation of a particular day, and it varies from time to time. The PV power output of the system is given by,[16]

$$
P_{p v-\text { generator }}=P_{m p-s t c} \times\left(\frac{G}{G_{s t c}}\right)\left[1+K_{t}\left(T_{c e l l}-T_{s t c}\right)\right]
$$

Where, $G_{s t c}$ is the standard test condition solar radiation, $\mathrm{G}$ is solar radiation $\left(\mathrm{W} / \mathrm{m}^{2}\right)$, $P_{m p-s t c}$ is the rated power of the module, $T_{s t c}$ is the temperature at standard test condition, $T_{\text {cell }}$ is the cell temperature and $K_{t}$ is the power temperature co-efficient. The temperature of the cell is calculated by [3]

$$
T_{\text {cell }}=T_{a}+\left[\frac{\text { n.temp }-20}{800}\right] G
$$

$T_{a}$ is the ambient temperature in degree Celsius, n.temp is the nominal temp (degree Celsius). The total power output of the panel is obtained by multiplying the power output of individual cells multiplied by the number of panels.

\subsubsection{Diesel generator}

The generator used in this study was $25 \mathrm{~kW}$, with an initial cost is $\$ 12,500$. The operation and maintenance cost was taken as $\$ 0.03$ /operation hour. The minimum load ratio is $25 \%$. The lifetime of the generator is taken as 15,000 hours. Fuel price in Somalia $1.1 /$ litres. $\mathrm{CO}_{2}$ emissions are $16.34 \mathrm{~g} / \mathrm{L}$, and unburned $\mathrm{HC}$ is $0.72 \mathrm{~g} / \mathrm{L}$ with other particulates $0.098 \mathrm{~g} / \mathrm{L}$.[14] The diesel generator is a conventional system and ensures the reliability of the system. The modelling of fuel consumption of the diesel generator is done by HOMER using the formula, [14] [17]

$$
F_{\text {gen }}=F_{0} \times P_{\text {gen-rated }}+F_{1} \times P_{\text {gen-out }}
$$

$F_{0}$ is the fuel curve intercept coefficient $F_{1}$ is the fuel curve slope $P_{\text {gen-rated }}$ is the rated capacity of the generator $(\mathrm{kW})$ and $P_{\text {gen-out }}$ is the electrical output of the generator. In HOMER the electrical efficiency is the ratio of electrical energy coming out to the chemical energy of fuel going in, [14] [18]

$$
\begin{gathered}
\eta_{\text {gen }}=\frac{3.6 \times P_{\text {gen }}}{m_{\text {fuel }} \times L H V_{\text {fuel }}} \\
R F=\left(1-\frac{\sum P_{\text {diesel }}}{\sum P_{\text {renew }}}\right) \times 100
\end{gathered}
$$

Where, $P_{\text {diesel }}$ is the power output of diesel generator and $P_{\text {renew }}$ is the power output of the renewable source.

\subsubsection{Battery Storage}

In renewable hybrid systems, the battery capacity fluctuates due to the randomness of solar and wind energy. The battery comes into use when renewable sources are not available or is producing low and cannot meet the load demand. The size of the battery depends on a number of factors such as energy demand, the depth of discharge, temperature correction, and a lifetime of the battery and the rated capacity of the battery. The charge capacity of battery to supply the total load can be expressed as [19]

$$
C_{b}=\frac{E_{l} \times S_{d}}{V_{b}(D O B)_{\max } T_{f c} \eta_{b}}
$$

Where $E_{l}$ is the electrical load in (Wh), $S_{d}$ is the battery autonomy in days, $V_{b}$ is the battery voltage $(\mathrm{V}),(D O B)_{\max }$ is the maximum depth of discharge of storage, $T_{f c}$ is the correction factor of the temperature, and $\eta_{b}$ is the efficiency of the battery. The state of charge (SOC) 
of the battery depends upon the production from renewables, its previous SOC, and the load demand. During the charging state, i.e., renewable production higher than the load demand, SOC can be expressed as [20]

$$
\operatorname{SOC}(t)=\operatorname{SOC}(t-1) \times(1-\sigma)+\left[E_{\text {hybrid }}(t)-\frac{E_{l}(t)}{\eta_{\text {inv }}}\right] \cdot \eta_{b}
$$

During discharging, where renewable production is less than the demand the SOC is determined by, [21]

$$
\operatorname{SOC}(t)=\operatorname{SOC}(t-1) \times(1-\sigma)+\left[\frac{E_{l}(t)}{\eta_{\text {inv }}}-E_{\text {hybrid }}(t)\right]
$$

Where $(\mathrm{t})$ is the state of battery at the hour $(\mathrm{t}), \mathrm{SOC}(\mathrm{t}-1)$ is the previous SOC at $(\mathrm{t}-1), \sigma$ is the discharging rate of the battery, $E_{\text {Hybrid }}(t)$ is total energy generated from PV and wind(kWh), $E_{l}(t)$ the load requirement at the time $(t), \eta_{i n v}$ and $\eta_{b}$ is the efficiency of inverter and battery charging efficiency respectively. [22]

$$
E_{\text {Hybrid }}(t)=E_{\text {Wind }}(t)+E_{P V}(t)
$$

$E_{\text {Wind }}(t), E_{P V}(t)$ are energy generated from wind and PV, respectively, in $\mathrm{kWh}$. The storage bank life of the battery is calculated in HOMER using,[14] if limited by throughput.

$$
R_{\text {battery }}=\frac{N_{\text {battery }} \times Q_{\text {lifetime }}}{Q_{\text {throughput }}}
$$

If limited by throughput and time.

$$
R_{\text {battery }}=\left(\frac{N_{\text {battery }} \times Q_{\text {lifetime }}}{Q_{\text {throughput }}}, R_{\text {battery, } f}\right)
$$

if limited by time.

$$
R_{\text {Battery }}=R_{\text {Battery, } f}
$$

$\mathrm{R}$ is storage life in years, $N_{\text {battery }}$ is the number of batteries in storage, $Q_{\text {Lifetime }}$ is the throughput of a single battery in $\mathrm{kWh}, Q_{\text {throughput }}$ and is the storage throughput annually (kWh/year), $R_{\text {Battery, } f}$ is the period of time the storage will last before replacement. The autonomy period of battery $A_{\text {Battery }}$ is defined as the ratio of battery bank size to that of the total load demand,[14]

$$
A_{\text {battery }}=\frac{N_{\text {battery }} \cdot V_{\text {nom }} \cdot Q_{\text {nom }}\left(1-\frac{Q_{\min }}{100}\right) \times\left(\frac{24 h}{\text { day }}\right)}{L_{\text {av.prim }}\left(\frac{1000 w h}{k w h}\right)}
$$

$N_{\text {Battery }}$ is the number of batteries, $V_{\text {nom }}$ is the nominal voltage of a single battery $(\mathrm{V}), Q_{\text {nom }}$ is the nominal capacity of a single battery in Ampere hour (Ah), $Q_{\min }$ is the minimum SOC of battery in percentage and $L_{a v . p r i m}$ is the average primary load ( $\mathrm{kWh} /$ day).

\subsubsection{Converter}

A bidirectional converter was used in this study, and it maintains the flow of alternating current and direct current, i.e., acts as both rectifier and converter. The capital cost of the converter was taken as $\$ 300$, and the replacement cost was taken as $90 \%$ of the capital cost, i.e., \$270. The operation and maintenance cost was neglected. Efficiency was taken as $90 \%$, and lifetime was assumed to be 15 years. The mathematical model is given below, [14] [23]

$$
E_{i n v(t)}=E_{p v(t)} \times \eta_{i n v}
$$




$$
E_{\text {battery }}=\left[\frac{E_{\text {battery }(t-1)}-E_{l(t)}}{\eta_{\text {inv }} \times \eta_{\text {discharge }}}\right]
$$

Where, $E_{i n v(t)}$ is the energy output of inverter in $\mathrm{kWh}, E_{p v(t)}$ is the energy output from the PV system, $\eta_{i n v}$ is the inverter efficiency, $E_{\text {battery }}$ is the energy output from the battery, $E_{l(t)}$ is the energy consumed by the electric load $(\mathrm{kWh}), \eta_{\text {dischharge }}$ is the efficiency of battery discharge. The rectifier helps to charge the battery from the electricity generated by the wind turbine.

$$
\begin{gathered}
E_{r e c-o u t(t)}=E_{r e c-i n p(t)} \times \eta_{r e c} \\
E_{r e c-i n p(t)}=E_{w t(t)}+E_{d g(t)}-E_{l(t)}
\end{gathered}
$$

$E_{\text {rec-out }(t)}$ is the energy output from the rectifier in hour $t(\mathrm{kWh}), E_{\text {rec-inp }(t)}$ is energy input to the rectifier in $\mathrm{kWh}, \eta_{\text {rec }}$ is the rectifier efficiency, $E_{W T(t)}$ is the energy generated from the wind turbine per hour $(\mathrm{kWh}), E_{d g(t)}$ is the diesel generator output and $E_{l(t)}$ is the energy consumed by the load in $\mathrm{kWh}$.

\subsection{System Controller}

\subsubsection{Load Following}

In the load-following strategy, the generator produces only enough power to satisfy the load demand. The battery is charged by renewable sources, mostly when the penetration is higher.

\subsubsection{Cycle Charging}

In this type of charging, batteries are charged to the set point given. The number of starts of the generator is reduced. Also, the charging- discharging cycle of the battery is also reduced.

\subsubsection{Combined Dispatch}

Combined dispatch is the best strategy as it improves the performance of the system than the LF and CC strategy. It makes efficient use of a generator. It utilises the CC strategy when the load is low and LF when the load is higher. Figure 8 shows combined dispatch flow chart. CD calculates the cost of every decision to obtain the lowest cost-effective solution. Three cases can be discussed. [24]

- The first case is when the electricity provided by the generator only feeds the load without charging the battery.

- The second case is when the generator meets the loads and also charges the battery with the remaining electricity.

- The next case is when the battery feeds the load alone. This can be explained as, if the renewable energy production is higher than the load demand, the power flow follows CC/LF strategy. If renewable production is low, it follows a different procedure.

If the $S O C=S O C_{m i n}$, The controller then compares the amount of money needs to run the generator at max capacity to feed the load, and by using the excess electricity, it charges the battery with that of feeding the load without charging the battery. The least cost is selected from both cases. If the $S O C>S O C_{\text {min }}$, three cases are compared, and one with the least cost is selected. The power flow is based on the least cost among the three cases. The cases are; Numbered lists can be added as follows:

1. Cost when the generator serves the load, and no battery is charged.

2. Run the generator at full capacity and serving the load and by excess electricity charging the battery.

3. Cost when the battery is discharged.

8.png 8.pdf 8.jpg 8.mps 8.jpeg 8.jbig2 8.jb2 8.PNG 8.PDF 8.JPG 8.JPEG 8.JBIG2 8.JB2 8.eps

Figure 8. Combined Dispatch Flow chart. 


\subsection{Final system configuration}

Figure 9 shows the final design layout. The diesel generator and the wind turbines are connected to the AC bus bar with the PV system and battery connected to the DC bus bar. The loads are completely AC in this study, and a multi-directional converter is connected to the AC and DC bus bars, which has both inverter and converter configuration.

9.png 9.pdf 9.jpg 9.mps 9.jpeg 9.jbig2 9.jb2 9.PNG 9.PDF 9.JPG 9.JPEG 9.JBIG2 9.JB2 9.eps

Figure 9. Final system configuration

\subsection{Economic Calculations}

The total life cycle cost (NPC), which is the total sum of initial capital cost, replacement cost, operating and maintenance cost, and the fuel cost and salvage cost was calculated. The total NPC can be expressed as,[14].

$$
\begin{aligned}
& N P C_{\text {total }}=\frac{C_{a n n, t o t}}{C R F} \\
& C_{a n n, \text { tot }}=\Sigma_{N=1}^{N_{p v}} C_{a n n, p v}+\Sigma_{N=1}^{N_{W T}} C_{a n n, W T}+\Sigma_{N=1}^{N_{D G}} C_{a n n, D G}+\Sigma_{N=1}^{N_{b a t t}} C_{a n n, b a t t}+\Sigma_{N=1}^{N_{c o n v}} C_{a n n, c o n v} \\
& C R F=\frac{i(1+i)^{n}}{(1+i)^{n}-1} \\
& i=\frac{i^{\prime}-f}{1+f}
\end{aligned}
$$

$C_{a n n, x}$ is the annualized cost of each component, $\mathrm{x}$ being the components in the hybrid system, and is the sum of total capital cost, O\&M, fuel cost, and salvage cost of the individual system. LCOE of the system is the cost per $\mathrm{kWh}$ of electricity produced and is found by HOMER using, [14]

$$
L C O E=\frac{C_{a n n, t o t}}{E_{\text {served }}}
$$

$C_{a n n, t o t}$ is the total annualized cost $(\$ / \mathrm{kWh})$, and $E_{\text {served }}$ is the total electrical load in $\mathrm{kWh} /$ year.

\subsection{Techno-Economic Constraints}

Constraints are important to obtain realistic solutions to the system. In this study, the discount rate is taken at $7.8 \%$. An increase in the discount rate increases the risk perception. So, in order to minimize the risk, a low discount rate is considered for this study [25]. The inflation rate is taken at $5.20 \%$ [26]. It is important to define this to a realistic value as it determines the economics of the system. Project lifetime is taken as 20 years, and no capacity shortage is considered in this study as the system designed is to be completely reliable.

\subsection{Sensitivity Analysis}

There can be a lot of uncertainties in the techno-economic analysis. Previous studies show these uncertainties affect the economics of the system and play a key role in the success of a project [27] [28]. For this study, fuel cost, discount rate, load growth, wind turbine capital cost, PV panel capital cost, Wind resource, and solar resource are considered as the sensitivity parameters. The selected parameter was varied within $25 \%$ while keeping other parameters constant. The sensitivity model of the parameters with respect to NPC and COE was recorded in the form of a graph. In this study, sensitivity analysis is only performed on the optimal solution of Kabaal.

\section{Results}

The results of the four study sites and four system configurations are now presented. This includes optimal design and economically feasible solutions. The four system designs 
were a Wind-PV-battery-DG system, Wind-DG-battery system, PV-DG-battery system, and a conventional stand- alone DG.

\subsection{Kabaal}

For Kabaal, the most cost-effective solution is a WT-PV-DG-BATTERY system, which has an LCOE of $0.284 \$ / \mathrm{kWh}$, with CD as control strategy. See Table 4 . So, this combination of the system is selected for which includes $2,007 \mathrm{kWh}$ deferrable load. The system when simulated using LF and CC strategy gave LCOE of $0.315 \$ / \mathrm{kWh}$ and $0.321 \$ / \mathrm{kWh}$ respectively. The system contained no unmet load, which is important as this is developed for high reliability and zero outages. There was a surplus electricity production of 26,169 $\mathrm{kWh}$ /year, which is about $25 \%$ of the total. This can be used to power the neighbouring villages. This can be done either by storing excess power using the batteries and selling them to other consumers, and also by the peer to peer (P2P) energy trading method [29].

Table 4. Simulation result of Kabaal.

\begin{tabular}{lllll}
\hline Item & PV-WT-DG-BAT & PV-DG-BAT & WT-DG-BAT & DG only \\
\hline PV(kW) & 17.3 & 32.1 & 0 & 0 \\
WT(No) & 1 & 0 & 1 & 0 \\
DG(kW) & 25 & 25 & 25 & 25 \\
BAT(kWh) & 55 & 67 & 25 & 0 \\
CONVERTER(kW) & 11.8 & 15.4 & 4.43 & 0 \\
DISPATCH STRATEGY & CD & $\mathrm{CD}$ & $\mathrm{CD}$ & $\mathrm{CD}$ \\
NPC(\$) & 315,910 & 394,000 & 355,241 & 568,508 \\
COE(\$) & 0.284 & 0.354 & 0.319 & 0.511 \\
INITIAL COST(\$) & 164,077 & 117,312 & $109,549$. & 12,500 \\
OPERATING COST(\$) & 9,713 & 17,766 & 15,718 & 35,570 \\
R.F(\%) & 79 & 55.4 & 60 & 0 \\
\hline
\end{tabular}

10.png 10.pdf 10.jpg 10.mps 10.jpeg 10.jbig2 10.jb2 10.PNG 10.PDF 10.JPG 10.JPEG 10.JBIG2 10.JB2 10.eps

Figure 10. Production of components in Kabaal.

Figure 10 shows the production of the components in each month. Production from the PV was nearly the same throughout the year. The wind speed was high for June, July, and August, and it resulted in the graph in figure 10. From the simulation, the mean output of the wind turbine and capacity factor was $6.44 \mathrm{~kW}$ and $43.3 \%$, respectively. The total hours of operation obtained were 8,196 per year. Wind penetration was $79.2 \%$, and the individual Levelized cost was $0.121 \$ / \mathrm{kWh}$. The mean output from the PV is $3.19 \mathrm{~kW}$, $76.6 \mathrm{kWh} /$ day. The capacity factor was $19.2 \%$. PV penetration for the location was $39.3 \%$ and had a Levelized cost of $0.101 \$ / \mathrm{kWh}$. The hour of operation of PV was 4,346 hours / year. For the generator, the hours of operation were 1,645 hours per year. It has 662 starts per year, and the operational life obtained is 9.12 years. The fixed generation cost of the diesel generator is $1.71 \$ / \mathrm{kWh}$. The mean electrical output is $9.61 \mathrm{~kW}$. Another important aspect is fuel consumption, and the generator consumed 5,671 litres/year, i.e., 0.6471 / hour. The string size of the battery is one, and these were connected in parallel. The total number of batteries was 55 . The nominal capacity of the battery was $55 \mathrm{kWh}$, out of which $33 \mathrm{kWh}$ is usable. The expected lifetime of the battery is 5.37 years. There is a loss of $1,832 \mathrm{kWh} /$ year and a storage depletion of $8.70 \mathrm{kWh} /$ year. The annual throughput was $8,199 \mathrm{kWh} /$ year. The system had an IRR of $16.5 \%$, which is above the threshold of $12 \%$, in which the mini-grid operators in Africa consider a project to be viable [30]. The ROI of the system obtained is $12 \%$. The payback year calculated was 5.8 years. Table 5 shows the emission comparison of selected system with that of a diesel generator system. 
Table 5. Emission Comparision

\begin{tabular}{llll}
\hline POLLUTANT & PV-WT-DG-BAT & DG ONLY SYSTEM & UNITS \\
\hline Carbon dioxide & 13,822 & 74,306 & $\mathrm{Kg} /$ year \\
Carbon monoxide & 86.3 & 464 & $\mathrm{Kg} /$ year \\
Unburnt Hydrocarbons & 3.80 & 20.40 & $\mathrm{Kg} /$ year \\
Particulate matters & 0.517 & 2.78 & $\mathrm{Kg} /$ year \\
Sulphur dioxide & 33.8 & 182 & $\mathrm{Kg} /$ year \\
Nitrogen oxides & 81.1 & 436 & $\mathrm{~kg} /$ year \\
\hline
\end{tabular}

11.png 11.pdf 11.jpg 11.mps 11.jpeg 11.jbig2 11.jb2 11.PNG 11.PDF 11.JPG 11.JPEG 11.JBIG2 11.JB2 11.eps

Figure 11. Production of components in Ceel Buur.

\subsection{Ceel Buur}

As with Kabaal, in Ceel Buur, the four cases, Wind-PV-DG-bat, Wind-DG-bat, PVDG-bat, and DG alone system, were used. Detailed results of the simulation is given in table 6. From the simulation, the preferred solution selected is a WT-PV-DG-Battery system with CD and LCOE of $0.314 \$ / \mathrm{kWh}$. The system was also simulated using LF and CC dispatch strategy, and the COE was found to be $0.328 \$ / \mathrm{kWh}$ and $0.332 \$ / \mathrm{kWh}$, respectively. The wind turbine produced $43,877 \mathrm{kWh}$ /year, which is lower than the Kabaal. PV and DG produced $36,421 \mathrm{kWh}$ and 17,375kWh per year, respectively. Figure 11 shows the production of components in Ceel Buur. The renewable fraction of the system was 75.6\%. There was no unmet load, and the excess electricity was $22 \%$ of total production. The mean output of the wind turbine obtained from the simulation is $5.01 \mathrm{~kW}$. The wind penetration in Ceel Buur was $61.6 \%$. It operated for 7,918 hours per year. HOMER also calculated the Levelized cost, which was $0.156 \$ / \mathrm{kWh}$. The mean output from the PV system was $4.16 \mathrm{~kW}$. The capacity factor is $20.2 \%$, and the mean output per day being $99.8 \mathrm{kWh}$. The PV panels operated for 4,380 hours/year. The Levelized cost obtained was $0.095 \$ / \mathrm{kWh}$. The total hours of operation of the diesel generator in Ceel Buur were 1,677 hours per year. It had a total of 592 starts per year. The expected life was 8.94 years, and the fixed generation cost was $1.71 \$ / \mathrm{kWh}$. The mean electrical output from the generator was $6.25 \mathrm{~kW}$, and it consumed 6,127L of fuel per year. The specific fuel consumption was $0.353 \mathrm{~L} / \mathrm{kWh}$. For the battery component, the expected life was 4.98 years. Lifetime throughput $48,800 \mathrm{kWh}$ and storage wear cost was calculated to be $0.419 \$ \mathrm{kWh}$. HOMER also calculated a loss of 2,191 $\mathrm{kWh}$ /year and a storage depletion of $15.3 \mathrm{kWh} /$ year. Annual throughput was 9,809kWh. The IRR obtained for the system in Ceel Buur is $14 \%$. The return of investment (ROI) is

Table 6. Simulation result of Ceel Buur.

\begin{tabular}{lllll}
\hline Item & PV-WT-DG-BAT & PV-DG-BAT & WT-DG-BAT & DG only \\
\hline PV(kW) & 20.6 & 29.5 & 0 & 0 \\
WT(No) & 1 & 0 & 1 & 0 \\
DG(kW) & 25 & 25 & 25 & 25 \\
BAT(kWh) & 61 & 62 & 28 & 0 \\
CONVERTER(kW) & 13.4 & 14.8 & 3.95 & 0 \\
DISPATCH STRATEGY & CD & CD & CD & CD \\
NPC $(\$)$ & 348,974 & 385,932 & 412,467 & 568,508 \\
COE(\$) & 0.314 & 0.347 & 0.371 & 0.511 \\
INITIAL COST(\$) & 174,464 & 109,310 & 110,305 & 12,500 \\
OPERATING COST(\$) & 11,164 & 17,697 & 19,331 & 35,570 \\
R.F(\%) & 75.6 & 56.3 & 48.6 & 0 \\
\hline
\end{tabular}


Table 8. Simulation result of Saakov.

\begin{tabular}{lllll}
\hline Item & PV-WT-DG-BAT & PV-DG-BAT & WT-DG-BAT & DG only \\
\hline PV(kW) & 23.7 & 30.3 & 0 & 0 \\
WT(No) & 1 & 0 & 2 & 0 \\
DG(kW) & 25 & 25 & 25 & 25 \\
BAT(kWh) & 52 & 62 & 48 & 0 \\
CONVERTER(kW) & 14.1 & 16.3 & 7.48 & 0 \\
DISPATCH STRATEGY & CD & CD & CD & CD \\
NPC(\$) & 393,892 & 392,651 & 519,094 & 568,508 \\
COE(\$) & 0.354 & 0.353 & 0.467 & 0.511 \\
INITIAL COST(\$) & 179,719 & 111,536 & 227,466 & 12,500 \\
OPERATING COST(\$) & 13,702 & 17,952 & 18,657 & 35,570 \\
R.F(\%) & 68.5 & 55.1 & 53.1 & 0 \\
\hline
\end{tabular}

12.png 12.pdf 12.jpg 12.mps 12.jpeg 12.jbig2 12.jb2 12.PNG 12.PDF 12.JPG 12.JPEG 12.JBIG2 12.JB2 12.eps

Figure 12. Production of components in Saakov.

$10 \%$. The Simple payback year was found to be 6.4 years. Table 7 shows how emissions of the selected system are compared with the stand-alone diesel system.

Table 7. Emission Comparision

\begin{tabular}{llll}
\hline POLLUTANT & PV-WT-DG-BAT & DG ONLY SYSTEM & UNITS \\
\hline Carbon dioxide & 16,046 & 74,306 & $\mathrm{Kg} /$ year \\
Carbon monoxide & 100 & 464 & $\mathrm{Kg} /$ year \\
Unburnt Hydrocarbons & 4.41 & 20.40 & $\mathrm{Kg} /$ year \\
Particulate matters & 0.601 & 2.78 & $\mathrm{Kg} /$ year \\
Sulphur dioxide & 39.3 & 182 & $\mathrm{Kg} /$ year \\
Nitrogen oxides & 94.1 & 436 & $\mathrm{~kg} /$ year \\
\hline
\end{tabular}

\subsection{Saakov}

For Saakov, the most cost-effective solution is the system with PV-DG-Battery. Table 8 shows the simulation results obtained using different configurations. Saakov is a less windy location which has an average wind speed of $4.7 \mathrm{~m} / \mathrm{s}$ at $50 \mathrm{~m}$. This is low for the $15 \mathrm{~kW}$ wind turbine to perform. Again, for Saakov, the control strategy used is combined dispatch. The COE while using CC and LF for the PV-DG-battery system was $\$ 0.367 / \mathrm{kWh}$ and $\$ 0.356 / \mathrm{kWh}$, respectively. Total production from the PV system was $52,874 \mathrm{kWh} /$ year, and the $25-\mathrm{kW}$ generator produced $31,989 \mathrm{kWh} /$ year. The monthly electricity production from generator and PV is shown in figure 12. Excess electricity produced by the system was $8,748 \mathrm{kWh} /$ year, which is about $10.3 \%$ of the total production. The mean output from the PV panel was $6.04 \mathrm{~kW}$ and $145 \mathrm{kWh} /$ day. For PV, the hours of operation were 4380 hours per year and had a capacity factor of $19.8 \%$. The PV penetration level was $73 \%$. The diesel generator accounted for a total of $44.9 \%$ of total energy generation in Saakov and had a start of 793 times. The total hours of operation throughout the year and lifetime was calculated to be 2,914 hours and 5.15 years, respectively. The fixed generation cost was $\$ 1.71 /$ hour. The mean electrical output obtained was $11 \mathrm{~kW}$. The fuel consumption was 11,137 litres i.e. $0.348 \mathrm{~L} / \mathrm{kWh}$. The storage wear cost of the battery was $\$ 0.419 / \mathrm{kWh}$. Lifetime throughput was $49,600 \mathrm{kWh}$, and the expected life was around 3.80 years. Annual throughput was $12,749 \mathrm{kWh} /$ year, and there was a loss of $2,849 \mathrm{kWh} /$ year. The IRR of the system was $17.6 \%$ and an ROI of $12.8 \%$ was obtained. The simple playback year was 5.5 years. The selected system emitted $29,156 \mathrm{Kg}$ of carbon per year compared to $74,306 \mathrm{Kg}$ of that of DG only system. 
Table 10. Simulation result of Baki.

\begin{tabular}{lllll}
\hline Item & PV-WT-DG-BAT & PV-DG-BAT & WT-DG-BAT & DG only \\
\hline PV(kW) & 21.6 & 28.9 & 0 & 0 \\
WT(No) & 1 & 0 & 1 & 0 \\
DG(kW) & 25 & 25 & 25 & 25 \\
BAT(kWh) & 53 & 58 & 29 & 0 \\
CONVERTER(kW) & 15.3 & 15.7 & 3.76 & 0 \\
DISPATCH STRATEGY & CD & CD & CD & CD \\
NPC(\$) & 380,196 & 371,076 & 473,948 & 568,508 \\
COE(\$) & 0.342 & 0.333 & 0.426 & 0.511 \\
INITIAL COST(\$) & 106,783 & 106,782 & 121,490 & 12,500 \\
OPERATING COST(\$) & 16,908 & 17,952 & 22,548 & 35,570 \\
R.F(\%) & 72.20 & 58.6 & 38.6 & 0 \\
\hline
\end{tabular}

Table 9. Emission Comparision

\begin{tabular}{llll}
\hline POLLUTANT & PV-DG-BAT & DG ONLY SYSTEM & UNITS \\
\hline Carbon dioxide & 29,156 & 74,306 & $\mathrm{Kg} /$ year \\
Carbon monoxide & 182 & 464 & $\mathrm{Kg} /$ year \\
Unburnt Hydrocarbons & 8.02 & 20.40 & $\mathrm{Kg} /$ year \\
Particulate matters & 1.09 & 2.78 & $\mathrm{Kg} /$ year \\
Sulphur dioxide & 71.4 & 182 & $\mathrm{Kg} /$ year \\
Nitrogen oxides & 171 & 436 & $\mathrm{~kg} /$ year \\
\hline
\end{tabular}

\subsection{Baki}

From the simulation, it has been found that PV-DG-battery was the cost-optimal solution. This site lies in a low wind speed location, so the system with wind turbines are not economically viable. The LCOE of the selected location was $\$ 0.333 / \mathrm{kWh}$. Solar PV constitutes 55,952kWh/year and DG constitutes 29,445kWh/year. Total production was $85,397 \mathrm{kWh} /$ year.

13.png 13.pdf 13.jpg 13.mps 13.jpeg 13.jbig2 13.jb2 13.PNG 13.PDF 13.JPG 13.JPEG 13.JBIG2 13.JB2 13.eps

Figure 13. Production of components in Baki.

Figure 13 shows the total production of respective components per month. Excess electricity in this system was $10.6 \%$ of the total production. The rated capacity of PV was $28.8 \mathrm{~kW}$ and had a mean output of $6.39 \mathrm{~kW}$ and $153 \mathrm{kWh} /$ day. The capacity factor was obtained to be $21.1 \%$. PV penetration percentage was $78.6 \%$. The PV operated for 4,344 hours per year, and the Levelized cost of PV was $\$ 0.0877 / \mathrm{kWh}$. The diesel generator in this system operates for 2,595 hours / year. It has a number of starts of 640 per year and an operational life of 5.78 years. The capacity factor was $13.4 \%$. The fixed generation cost was $\$ 1.71 / \mathrm{kWh}$. The mean electrical output was $11.3 \mathrm{~kW}$. It consumes 10,179 litres of diesel/year. The specific fuel consumption was $0.34 \mathrm{~L} / \mathrm{kWh}$. The nominal capacity of the battery unit was $58 \mathrm{kWh}$. The storage wear cost was $\$ 0.419 / \mathrm{kWh}$. Lifetime throughput was $46,400 \mathrm{kWh}$, and the expected life was 3.54 years. There was a storage depletion of $9.41 \mathrm{kWh} /$ year and a loss of 2,930kWh/year. Throughput was $13,110 \mathrm{kWh}$ annually. The IRR of the system was $19.9 \%$, and the return of investment, ROI was $14.8 \%$. The simple payback year is calculated to be 4.9 years. Table 11 gives a detailed emission of the PV-DG system in Baki. 
Table 11. Emission Comparision

\begin{tabular}{llll}
\hline POLLUTANT & PV-DG-BAT & DG ONLY SYSTEMS & UNITS \\
\hline Carbon dioxide & 26,510 & 74,306 & $\mathrm{Kg} /$ year \\
Carbon monoxide & 165 & 464 & $\mathrm{Kg} /$ year \\
Unburnt Hydrocarbons & 7.29 & 20.40 & $\mathrm{Kg} /$ year \\
Particulate matters & 0.992 & 2.78 & $\mathrm{Kg} /$ year \\
Sulphur dioxide & 64.90 & 182 & $\mathrm{Kg} /$ year \\
Nitrogen oxides & 156 & 436 & $\mathrm{~kg} /$ year \\
\hline
\end{tabular}

\subsection{Sensitivity Results}

The sensitivity characteristic model for NPC and COE are shown in figure 14 . As seen from the graph, the COE of the system is most sensitive to variation in Wind resources in Kabaal, followed by the discount rate, wind turbine capital cost, and discount rate. The load and solar GHI are having the least effect in the COE of the selected system. For the case of NPC, the wind resources and load demand growth had a more significant deviation from the base value, whereas Solar GHI and PV capital cost had the least deviation.

\section{4.png 14.pdf 14.jpg 14.mps 14.jpeg 14.jbig2 14.jb2 14.PNG 14.PDF 14.JPG 14.JPEG 14.JBIG2 14.JB2 14.eps}

Figure 14. Sensitivity Analysis.

\subsection{Discussion and Validation of Results}

For the different locations of Kabaal, Ceel Buur, Saakov, and Baki, the results showed that the hybrid renewable system is an appropriate technology for their energy crisis. The LCOE and the Net Present Cost of the Hybrid system in all the locations studied were lower than the cost of electricity while using the DG system alone and lower than the price of grid-connected electricity in Somalia. Clearly, the price of electricity in Somalia is high between $\$ 0.5-\$ 1.5 / \mathrm{kWh}$. Furthermore, the studies outlined that high wind speed locations were more economical for hybrid systems in Somalia. Carbon emissions were substantially reduced by the hybrid systems, 80\% in Kabaal, 78\% in Ceel Buur, 60\% in Saakov, and 64\% in Baki.

The system is comparable to other studies such as by Tahir Matallah, Nahed Ghodhbane [31] where they modelled a hybrid system in Tunisia and the LCOE obtained was $\$ 0.26 / \mathrm{kWh}$ and $\mathrm{CO}_{2}$ emission by $29 \%$ than by using DG, Olatomiwa \& Blanchard [3], simulated a system for rural health care in Nigeria, and the COE was $\$ 0.27 / \mathrm{kWh}$ for the location considered and the carbon dioxide reduction obtained was about $90 \%$. The studied system was also comparable to other studies such as a microfinance institution in Nigeria by Ayodele \& Mishra [32], where the COE obtained was $\$ 0.66 / \mathrm{kWh}$, and there was a reduction of 50\% in $\mathrm{CO}_{2}$. From Aghenta \& Iqbal's [23] modelling of a hybrid system for a house in Benin, a COE of $\$ 0.4734 / \mathrm{kWh}$ was obtained. The COE is so low for some of the studies due to the selection of economic constraints such as discount rate and inflation rate, and also due to the greater availability of solar and wind resources. The system shows low COE when these values are high. In this study, we used an accurate inflation rate based on the World Bank data for Somalia.

The control strategies used in the study by Ansong[33], Sigarchian[34], Rezzok, and Mellit [35] were Load Following, but a study by Blanchard [3] utilized by Cycle Charging. C.K. Seng [24] performed a study on both CC and LF and concluded that the CC strategy obtained the most efficient result. All the papers studied either used CC or LF strategy. This study used a Combined Dispatch strategy and compared the results obtained with that while using CC and LF strategy whereby CC and LF control strategies were giving higher $\mathrm{COE}$ than the $\mathrm{CD}$ strategy. $\mathrm{CD}$ is also more environmentally beneficial than the other two methods as the emission level were lower due to the efficient use of generator. 
If more studies are done on CD technology, the previous studies may achieve even better results. It should be noted that the wind data obtained from Global Wind Atlas contains multiple constraints, and the associated uncertainties could lead to slightly incorrect wind speed data. Zahoa \& Guo [36] used a more accurate model, which was a combination of numerical simulation, statistical modelling, and optimization. Accurate wind data will make the system more realistic. Also, a tracking system was not included in this study, and a research lead by Rahimi [37] found that using hybrid wind sun-tracking improves the performance of the PV cell by $49 \%$. The load profile used in this study was estimates of load patterns, which will change for individual houses, schools, and the health clinic. Aghenta [23] used B-opt software to determine the energy consumption in a house in Nigeria accurately and then model the hybrid system. Previous studies [38] [39] [40] show that the load consumption, Discount rate, capital costs, solar and wind resources, Fuel cost all have an impact on the micro grids. From the sensitivity analysis in Kabaal, it is seen that the increase in wind speed has a high impact on the COE and NPC of the system in this location as the wind turbine performs better.

\section{Conclusion}

The study shows that Somalia has excellent wind energy potential, especially in the coastal regions. Still, access to electricity in Somalia is very low. Moreover, the cost of mains electricity in Somalia is high ranging from $\$ 0.5$ to $\$ 1.50$ per $\mathrm{kWh}$. So, it is assumed that most poor people in this country cannot afford this high price. Apart from the high cost of electricity, the study also identified the lack of reliable sources of electricity in health clinics and schools in regions of Africa. The literature even found that unreliable electricity causes child mortality and maternal mortality. Most remote places use diesel generators for electricity as grid extension to rural regions is very expensive. The use of diesel generators also emits a large amount of carbon dioxide and other pollutants.

This paper presents a solution to tackle the high cost of electricity, the unreliability of power and pollution. An off-grid hybrid system configured as a Wind-PV-DG-battery was used in this study. A total of four locations in Somalia were selected for the study (Kabaal, Ceel Burr, Saakov, and Baki). Different configurations with PV- Wind- DG and battery were analysed under different solar, wind, and temperature conditions. The load used in this study comprised a health clinic, school, 200 households, and two water pumps to provide water supply to the community. The load calculation was carried out by the analysis of electrical equipment used and the daily hours of operation. The total load of the system selected consisted of $195.03 \mathrm{kWh} /$ day primary load and $5.5 \mathrm{kWh} /$ day deferrable load. The software used in this analysis was HOMER. This modelling software optimizes different configurations to give the cost-optimal solution with zero outages.

The study identified that Kabaal and Ceel Burr were located in the region of high wind potential, and a hybrid system consisting of Wind-PV-DG-Battery was the best solution. Kabaal and Ceel Buur have COE of $\$ 0.297 / \mathrm{kWh}$ and $\$ 0.326 / \mathrm{kWh}$, respectively. NPC of the locations are $\$ 330,440$ and $\$ 363,180$. For the less windy locations, Saakov and Baki, the hybrid system configuration of PV-DG-Battery was the best solution having COE of $\$ 0.353 / \mathrm{kWh}$ and $\$ 0.333 / \mathrm{kWh}$, respectively. Saakov and Baki have an NPC of $\$ 392,651$ and $\$ 371,076$. The study also identified that Combined Dispatch offered the best control strategy for the locations since it gives the lowest COE compared to the LF and CC strategies. Also, the $\mathrm{CD}$ had lower carbon emission than $\mathrm{CC}$ and $\mathrm{CF}$ strategy. Emissions of $\mathrm{CO}_{2}$ from a stand-alone diesel generator system were $74,306 \mathrm{~kg} /$ year, and the hybrid systems identified reduced this by $80 \%$ in Kabaal, $78 \%$ in Ceel Buur, $60 \%$ in Saakov, and $68 \%$ Baki. The study also showed that the economic performance of the system is susceptible to wind energy resource, load growth, and discount rate. So, to conclude, this study shows how effective hybrid systems can be in remote rural regions. The study also provides information on how effective control strategies help to improve the system. Due to its low cost of energy, reliability, low emission, more studies in this field can help to improve the electrical scenario in remote places across the globe. 
Author Contributions: Conceptualization, S.K; writing-orginal draft preperation, S.K; writingreview and editing, R.B; supervision, R.B. All authors have read and agreed to the published version of the manuscript.

Funding: The research received no external funding.

Acknowledgments: The authors gratefully acknowledge the support provided by Enbreeze GmbH, Germany and CREST, Loughborough.

Conflicts of Interest: The authors declare no conflict of interest.

$\begin{array}{ll}\text { Abbreviations } \\ \text { CC } & \text { Cycle Charging } \\ \text { CD } & \text { Combined Dispatch } \\ \text { COE } & \text { Cost Of Electricity } \\ \text { DG } & \text { Diesel Generator } \\ \text { E } & \text { Energy } \\ \text { GHI } & \text { Global Horizontal Radiation } \\ \text { GWA } & \text { Global Wind Atlas } \\ \text { IRR } & \text { Internal Rate of return } \\ \text { LCOE } & \text { Levalized Cost of Electricity } \\ \text { LF } & \text { Load Following } \\ \text { MPPT } & \text { Maximum Power Point Tracking } \\ \text { NPC } & \text { Net Present Cost } \\ \text { NREL } & \text { National Renewable Energy Laboratory } \\ \text { PV } & \text { Photovoltaics } \\ \text { RF } & \text { Renewable Fraction } \\ \text { ROI } & \text { Return of Investment } \\ \text { SC } & \text { Salvage Cost } \\ \text { SOC } & \text { Sate of Charge }\end{array}$

\section{References}

1. Sustainable Energy for All, Electricity for all in Africa. Available online: https://www.seforall.org/electricity-for-all-in-africa, (Accessed on May 2020).

2. The World Bank, Electrification Efforts in Sub-Saharan Africa. Available online: https://www.worldbank.org/en/region/afr/ publication/electricity-access-sub-saharan-africa, (Accessed on April 2020).

3. Olatomiwa, L.; Blanchard, R.; Mekhilef, S.; Akinyele, D. Hybrid renewable energy supply for rural healthcare facilities: An approach to quality healthcare delivery. Sustainable Energy Technologies and Assessments 2018, 30, 121-138.

4. Longe, O.; Rao, N.; Omowole, F.; Oluwalami, A.; Oni, O. A Case study on off-grid microgrid for universal electricity access in the Eastern Cape of South Africa. International Journal of Energy Engineering 2017, 7, 55-63.

5. The World Bank, Africa infrastructure: Electricity. Available online: https:/ / databank.worldbank.org/reports.aspx?Id=1031e6 fd\&Report_Name=Africa-electricity-tariff, (Accessed on may 2019).

6. USAID, Somalia: Power Africa Factsheet. Available online: https://www.usaid.gov/powerafrica/wherewework/somalia, (Accessed on March 2020).

7. USAID, Powering Health: Electrification option for rural health centers. Available online: http://www.poweringhealth.org/ Pubs/PNADJ557.pdf, (Accessed on March 2020).

8. Ye, Y.; Koch, S.F.; Zhang, J. Determinants of household electricity consumption in South Africa. Energy economics 2018, 75, 120-133.

9. Transitional Federal Republic of Somalia Ministry of Education, Culture and Higher Education. Ministry of Education, Culture and Higher Education. Available online: https:/ /www.somalia.gov.so/ministries/, (Accessed on May 2011).

10. Lyden, A.; Pepper, R.; Tuohy, P.G. A modelling tool selection process for planning of community scale energy systems including storage and demand side management. Sustainable cities and society 2018, 39, 674-688.

11. National Renewable energy Lab. Available online: https://www.nrel.gov//, (Accessed on April 2020).

12. Global wind atlas, Energy data Info. Available online: https://globalwindatlas.info/, (Accessed on April 2020).

13. Enbreeze GmbH. Data sheet 15kW. Available online: http://enbreeze.com/, (Accessed on April 2020).

14. Lambert, T.; Gilman, P.; Lilienthal, P. Micropower system modeling with HOMER. Integration of alternative sources of energy 2006, 1, 379-385.

15. NREL, HOMER database. Available online: https://www.homerenergy.com/, (Accessed on April 2020).

16. Ismail, M.S.; Moghavvemi, M.; Mahlia, T. Techno-economic analysis of an optimized photovoltaic and diesel generator hybrid power system for remote houses in a tropical climate. Energy conversion and management 2013, 69, 163-173. 
17. Dufo-López, R.; Bernal-Agustín, J.L. Multi-objective design of PV-wind-diesel-hydrogen-battery systems. Renewable energy 2008, 33, 2559-2572.

18. Saheb-Koussa, D.; Koussa, M.; Belhamel, M.; Haddadi, M. Economic and environmental analysis for grid-connected hybrid photovoltaic-wind power system in the arid region. Energy Procedia 2011, 6, 361-370.

19. Schmitt, A.; Huard, G.; Jacquin, P. Recommendations for small renewable energy and hybrid systems for rural electrification, 2003.

20. Ayodele, T.; Munda, J. Potential and economic viability of green hydrogen production by water electrolysis using wind energy resources in South Africa. International Journal of Hydrogen Energy 2019, 44, 17669-17687.

21. Diaf, S.; Diaf, D.; Belhamel, M.; Haddadi, M.; Louche, A. A methodology for optimal sizing of autonomous hybrid PV/wind system. Energy policy 2007, 35, 5708-5718.

22. Aziz, A.S.; Tajuddin, M.; Adzman, M. feasibility analysis of PV/wind/battery hybrid power generation: a case study. International journal of renewable energy research 2018, 8, 661-671.

23. Aghenta, L.O.; Iqbal, M.T. Design and dynamic modelling of a hybrid power system for a house in Nigeria. International Journal of Photoenergy 2019, 2019.

24. Aziz, A.S.; Tajuddin, M.F.N.; Adzman, M.R.; Ramli, M.A.; Mekhilef, S. Energy management and optimization of a $\mathrm{PV} /$ diesel/battery hybrid energy system using a combined dispatch strategy. Sustainability 2019, 11, 683.

25. Oxera. Discount rates for low carbon and renewable generation technologies. Available online: https://www.oxera.com/wpcontent/uploads/2018/03/Oxera-report-on-low-carbon-discount-rates.pdf/, (Accessed on May 2020).

26. Trading Economics, Somalia Inflation Rate. Available online: https://tradingeconomics.com/somalia/inflation-cpi, (Accessed on Mayl 2020).

27. Lukuyu, J.M.; Blanchard, R.E.; Rowley, P.N. A risk-adjusted techno-economic analysis for renewable-based milk cooling in remote dairy farming communities in East Africa. Renewable energy 2019, 130, 700-713.

28. Halabi, L.M.; Mekhilef, S.; Olatomiwa, L.; Hazelton, J. Performance analysis of hybrid PV/diesel/battery system using HOMER A case study Sabah, Malaysia. Energy Conversion and Management 2017, 144, 322-339.

29. An, J.; Lee, M.; Yeom, S.; Hong, T. Determining the Peer-to-Peer electricity trading price and strategy for energy prosumers and consumers within a microgrid. Applied Energy 2020, 261, 114335.

30. Franz, M.; Hayek, N.; Peterschmidt, N.; Rohrer, M.; Kondev, B.; Adib, R.; Cader, C.; Carter, A.; George, P.; Gichungi, H.; others. Mini-grid Policy Tool-kit. Policy and business frameworks for successful mini-grid roll-outs, 2014.

31. Maatallah, T.; Ghodhbane, N.; Nasrallah, S.B. Assessment viability for hybrid energy system (PV/wind/diesel) with storage in the northernmost city in Africa, Bizerte, Tunisia. Renewable and Sustainable Energy Reviews 2016, 59, 1639-1652.

32. Ayodele, E.; Misra, S.; Damasevicius, R.; Maskeliunas, R. Hybrid microgrid for microfinance institutions in rural areas-A field demonstration in West Africa. Sustainable Energy Technologies and Assessments 2019, 35, 89-97.

33. Ansong, M.; Mensah, L.D.; Adaramola, M.S. Techno-economic analysis of a hybrid system to power a mine in an off-grid area in Ghana. Sustainable Energy Technologies and Assessments 2017, 23, 48-56.

34. Sigarchian, S.G.; Paleta, R.; Malmquist, A.; Pina, A. Feasibility study of using a biogas engine as backup in a decentralized hybrid (PV/wind/battery) power generation system-Case study Kenya. Energy 2015, 90, 1830-1841.

35. Rezzouk, H.; Mellit, A. Feasibility study and sensitivity analysis of a stand-alone photovoltaic-diesel-battery hybrid energy system in the north of Algeria. Renewable and Sustainable Energy Reviews 2015, 43, 1134-1150.

36. Zhao, J.; Guo, Z.; Guo, Y.; Zhang, Y.; Lin, W.; Hu, J. Wind resource assessment based on numerical simulations and an optimized ensemble system. Energy Conversion and Management 2019, 201, 112164.

37. Rahimi, M.; Banybayat, M.; Tagheie, Y.; Valeh-e Sheyda, P. An insight on advantage of hybrid sun-wind-tracking over sun-tracking PV system. Energy Conversion and Management 2015, 105, 294-302.

38. Murugaperumal, K.; Srinivasn, S.; Prasad, G.S. Optimum design of hybrid renewable energy system through load forecasting and different operating strategies for rural electrification. Sustainable Energy Technologies and Assessments 2020, $37,100613$.

39. Fodhil, F.; Hamidat, A.; Nadjemi, O. Potential, optimization and sensitivity analysis of photovoltaic-diesel-battery hybrid energy system for rural electrification in Algeria. Energy 2019, 169, 613-624.

40. Perez Garcia, A. Techno-economic feasibility study of a small-scale biogas plant for treating market waste in the city of El Alto, 2014. 